esta historia la concatenación no se realiza entre filosofemas o ideas abstractas, sino entre una serie de problemas concretos cuya solución se convierte, a la postre, nuevamente en problema. Los problemas que el hombre ha tenido que enfrentar y las soluciones que ha venido dando a los mismos, se van encadenando en una dialéctica sin fin. Esto es lo que se ha querido hacer patente en este libro".

Sea de todo esto lo que fuere, el libro es, sin duda, una excelente introducción histórica a la filosofía que prestará inapreciables servicios, entre otras razones porque, al señalar el horizonte histórico de la filosofía, no da por supuesta la información del estudiante que suponen los manuales introductorios de origen europeo, corrientes en nuestro medio.

\section{Jorge PoRtilla}

\section{Conciencia y posibilidad del mexi-} cano, por Leopoldo Zea. Colección México y lo Mexicano, Porrúa y Obregón, México, 1952.

América como conciencia, por Leopoldo Zea. Ediciones Cuadernos Americanos, $\mathrm{N}^{\circ}$ 30, México, 1953. El Occidente y la conciencia de México, por Leopoldo Zea. Colección México y lo Mexicano, Porrúa y Obregón, México, 1953.

Los títulos de los tres volúmenes que aquí vamos a comentar dan a simple vista la pauta de las preocupaciones de su autor. Leopoldo Zea, desde el principio de su brillante carrera, se ha distinguido por la originalidad y agudeza con que ha abordado el tema que nos es más propio: la posibilidad de una -filosofia mexicana, o mejor todavía, la posibilidad de una auténtica filosofía americana. Se comentan, pues, conjuntamente, estos trés libros porque están animados por tal espiritu, y por lo mis- mo, parten de ciertas bases que les son comunes.

Se quiere decir que si se hace una filosofía americana con la sola pretensión de que sea americana, tal filosofía estará condenada al fracaso, pues el sentido de esta investigación es considerar a lo americano no como fin en sí, sino como punto de partida para lograr un objetivo más amplio; alcanzar una verdad válida para todo hombre que se encuentre en una situación semejante a la nuestra. "Esta nuestra filosofía no deberá limitarse a los problemas propiamente americanos, a los de su circunstancia, sino a los de esta circunstancia más amplia, en la cual estamos insertos como hombres que somos, la llamada Humanidad... Hay que intentar hacer pura y simplemente Filosofía, que lo americano se dará por añadidura."

$\mathrm{Y}$ es que no hemos hecho auténtica filosofía porque hemos reflexionado sobre lo reflexionado por otros, hemos puesto atención a problemas surgidos en circunstancias ajenas, preocupándonos más por saber si somos o no filósofos, que por saber si estamos o no en el camino de la verdad, esperando la patente de filósofos que otorga la cultura europea. Debemos convencernos; pues, de que hay que filosofar sin preocuparnos de que esta actividad sea o no reconocida como filosofía; esto es, debemos partir de los problemas que plantea la realidad americana con aspiración a lograr una solución humana.

El americano tiene ahora motivos especiales para interrogarse por la posibilidad de una filosofía americana, y con ella, de una cultura también auténticamente americana, pues antes no había tenido necesidad de plantearse esta cuestión: "había vivido cómodamente cobijado por la sombra del árbol de la cultura europea", utilizando el instrumental que esta cultura proporcionaba, para resolver bien o mal sus problemas. Pero un buen dia "el hombre europeo -el cultivador del árbol abrigador - lo corta y. arroja al fuego por 
inútil" y el americano se encuentra "de golpe" con la historia, con la necesidad de hacerla, de crear una cultura propia. Americano y europeo se hallan en una situación semejante, ante el problema de resolver qué nuevas formas de vida han de adoptar frente a las nuevas circunstancias, que se presentan como cuestiones insolubles a la cultura que desaparece.

Para poder adoptar una actitud responsable ante la crisis actual es menester que tomemos conciencia de nuestra realidad mexicana y americana. Esta toma de conciencia se entiende de dos maneras: una, que es la asimilación por mexicanos y americanos de un pasado que se han empeñado en negar; el americano, al examinar su historia y confrontarla con la historia europea, la ha rechazado por inferior, no ha querido reconocer en ella una de sus dimensio. nes $y$, por tanto, ha rechazado una parte de su propio ser, una experiencia que, por no ser asimilada - hecha propia-, tiene el peligro de volver a repetirse. Tenemos que negar, sí, nuestro pasado, pero "con la mejor de las negaciones, la histórica. Si no queremos repetir la experiencia de nuestros antepasados viviéndola, es menester que la convirtamos en historia, en auténtica experiencia". Cuando se tiene esta conciencia, se alcanza también la comprensión histórica, que es la capacidad para colocar un determinado hecho en el lugar preciso que le corresponde en el presente, y a la vez, la capacidad de saber los motivos por los cuales este hecho sucedió y no puede volver a repetirse, a menos que se niegue la historia.

Conciencia es también convivencia, es un saber en común, un saber de los otros $y$ con los otros. En latín, conciencia significa complicidad, es decir, participación de los unos con los otros; mediante la toma de conciencia cada uno de nosotros, como hombre, tratará de hacerse cómplice de la existencia de los otros, o de hacer a éstos cómplices de la propia existencia. Este proceso, difícil y doloroso, se da a través de una serie de afirmaciones y negaciones, pues cada hombre le niega la humanidad al semejante al tratar de "cosificarlo" - convertirlo en útil, ponerlo a su ser. vicio-, y al propio tiempo se la afirma al exigir que éste reconozca la propia. Esta toma de conciencia se realiza en los hombres y en las culturas. América ha venido tomando conciencia de su realidad mediante un movimiento dialéctico en el que se ha enfrentado a las opiniones de Europa sobre su ser y las que ella misma ha deducido al confrontarlas con lo que es en sí misma.

El azar no cuenta para nada en el descubrimiento de América. América, dice Zea, fué buscada y descubierta porque el hombre europeo la necesitaba para proyectar sus nuevos ideales, ya que éstos no podian ser proyectados en el cielo, pues éste, gracias a la Nueva Física, se había convertido en algo frío e ilimitado, en un infinito muerto, mecánico. América es vista por la conciencia en crisis del hombre europeo como una tierra de promisión, como una tierra sin historia, como una tierra en la cual se podía iniciar una nueva vida, en la cual se podía volver a nacer, a re-nacer. Sin embargo, sus hombres y pueblos se ofrecen a la vista del europeo como criaturas extrañas, ajenas totalmente a sus puntos de vista $y$, por lo tanto, incomprensibles. de acuerdo. con sus categorias culturales. $Y$ al no poder comprenderlos, les niega a estos hombres la calidad de humanos; la cultura de los pueblos americanos es vista por sus "cristianos ojos" como "fruto demoniaco". Dios no parecia que hubiese podido crear un mundo cuyos hábitos y costumbres venían a ser como la negación permanente de una moral que él mismo había dictado. El Occidente, al considerar este mundo como obra del demonio, arrasa su cultura poniendo - superponiendo, pues no logra arrancarla- la propia.

En México, la dominación española 
impone, superpone, un orden social durante la colonia, en el que se distinguen cuatro clases sociales: los indios, que están en la base de esa sociedad; los mes. tizos, que oscilan entre lo español y lo indigena $y$ son rechazados por ambos extremos; los criollos, que aspiran a los puestos públicos más elevados, y los peninsulares que, en cuanto toman contacto con esta tierra, sienten a su pesar que se transforman. La dialéctica de la conciencia en México se va a realizar, por tanto, en dos sentidos, uno "horizontal" e'n que se va a luchar contra los pueblos imperialistas -España, los Es. tados Unidos y Francia- y uno vertical en que las diversas clases sociales van a pugnar entre sí.

El primer sector que responde a la incitación española es el sector de los criollos; ellos realizan la independencia política de México, pero no alteran el orden social establecido por España; simplemente pasan a ocupar los puestos políticos tan anhelados. La segunda respuesta es dada por los mestizos que, al intentar remediar su ambigua posición, se dan cuenta de que es la educación clerical la que mantiene el orden impuesto por España, y llevan a cabo la Reforma emancipando la mentalidad mexicana de los moldes que la habían conformado. La tercera es dada por los indios que, por primera vez en la historia mexicana, reclaman una mejor posición dentro del conglomerado social. Esto no quiere decir que la Revolución Mexicana haya sido exclusivamente realizada por los indios; su importancia radica precisamente en que todas las clases sociales participaron en ella, pero llevando el signo del indígena como lema: "Tierra y libertad." Las aspiraciones más urgentes del indio nos descubren el sen. tido de la Revolución.

El mexicano es lo que su historia lo ha hecho $y$, por lo mismo, buena o mala, tenemos que aceptarla, pues de lo contrario estamos negando una parte de nuestro propio ser. Por lo demás, nuestra situación actual no es una situa- ción cerrada como la del europeo. El mexicano es un hombre inserto en una situación límite, "porque está dentro de esa línea que separa formas contradictorias de lo humano, linea en la que todo puede ser posible. Agudo y difícil filo en el cual es imposible un largo equilibrio y si la permanente caida hacia un lado o hacia el otro". Lo que separa esa línea es lo que llamamos lo culto y lo bárbaro, lo anquilosado a fuerza de organización y prevención de todas las actitudes, y la libertad de movimientos sin sujeción racional alguna, como fuerza natural sin trabas. "En nuestro pueblo se encuentran todos los extremos sin que prevalezca ninguno de ellos. Podemos, por un lado, comprender los más altos valores universales $\mathrm{y}$, por otro, ser estrechamente provincianos. Dentro de esa línea en que nos encontramos se confunden aún lo mágico con lo científico, lo imaginario con lo real, el tabú con el obstáculo natural, la comunidad con la sociedad, la ley con la voluntad, lo mítico con lo religioso, la muerte con la vida."

El azar juega en este filo de posibilidades su mejor papel. Nada puede ser previsto aunque se formule todo lo posible, pues nuestra existencia obedece no a un "deber ser", sino a un "querer ser". Sin embargo, en medio de esta zozobra e inconsistencia, el mexicano se esfuerza inconscientemente por captar lo que puede ser permanente dentro de la vida del hombre, aspira a reconciliar todos los afectos y todas las posibilidades. En esta actitud adivina una totalidad que puede ser la solución de todas sus inseguridades. "Hombre de mil caras, tantas como la movible circunstancia le impone, sabe intuitivamen. te que éstas no son sino máscaras detrás de las cuales está un hombre que, al igual que todos los hombres, aspira a permanecer en sus obras rompiendo los límites que le han impuesto las circunstancias." Viviendo al dia, a pesar de todo, pero viviendo siempre, el mexicano puede ya ofrecer a la ahora 
en crisis cultura occidental - que tanto le ha regateado su humanidad - una gran experiencia, una experiencia que puede ser válida para este mundo que parece haber gastado su patrimonio de so. luciones trascendentales. y que se ve obligado a vivir dentro de soluciones de carácter limitado que habrán de ser continua y permanentemente renovadas.

Una evolución semejante a la nuestra parecen haber sufrido el resto de los países hispanoamericanos. También entre ellos hubo hombres que defendieron su humanidad del regateo que de ella hacía el Occidente; hubo quienes protestaron contra el injusto rebajamiento del indígena en el xvi, contra la discriminación que la modernidad europea hizo de nuestro continente, contra los reproches infundados del historicismo hegeliano en el xIX, $y$ hay quienes se aplican a desentrañar el problema que ha provocado el uso y el abuso de la técnica por la América Sajona.

Esta última cuestión conduce a Zea a tratar el tema de las relaciones entre las dos Américas. Mientras Hispanoamérica se empeñaba en desgarrarse a si misma tratando de arrancarse una parte del propio ser, todo acontecía de una manera natural en los Estados Unidos; la libertad había sido alcanzada como fruto maduro sin que implicara demasiados problemas, lo mismo que las más perfeccionadas instituciones políticas. Para el latinoamericano, la constitución de la América del Norte tenía algo que le daba esa seguridad nunca alcanzada por Hispanoamérica. Qué fuera ese algo, constituyó una de sus principales preocupaciones. "Por esta razón, quizá no se encuentra en la historia un ejemplo de la forma como un pueblo puede estar en la conciencia de otro como los Estados Unidos en la concien. cia de los pueblos hispanoamericanos." Unas veces simbolizando el máximo modelo de sus ideales, otras como la negación suprema de ellos, Norteamérica ha sido también para Hispanoamérica una de las fuentes de su sentimiento de infe- rioridad, ya que nuestros intentos de ser como ellos han culminado en ruidosos fracasos.

Sin embargo, la admiración ha ido menguando cada vez más, debido a la actitud agresiva que en diversas ocasiones ha tomado el pueblo anglosajón para sostener sus intereses materiales. ¿Entonces, por qué unas veces los admiramos y otras los rechazamos? Lo que sucede es que todo pueblo tiene siempre más de una faceta, que se hace patente en su trato con los otros. "Hispanoamérica ha sentido y sentirá siempre admi. ración por la Norteamérica de las libertades, por la Norteamérica de un Washington afirmando los derechos del hombre, por la de un Lincoln aboliendo la esclavitud, por la de un Roosevelt entendiendo la democracia en un sentido universal." Pero existe también otra Norteamérica frente a la cual el hispanoamericano se siente superior, "la expresada en ambiciones territoriales, la que habla de un 'destino manifiesto', la de las discriminaciones raciales y todos los imperialismos". Norteamérica, en su doble faceta, ha servido, pues, para que el hispanoamericano tome conciencia de sí mismo: frente a la Norteamérica positiva se han hecho patentes sus grandes defectos; frente a la negativa sus grandes cualidades.

Una falsa interpretación de la Norteamérica negativa ha hecho pensar que los Estados Unidos sólo poseen una capacidad material y no una espiritual, atribuyéndole a Hispanoamérica propiedades contrarias; tal interpretación es. falsa, pues cabe pensar que ambas Américas tienen capacidades semejantes, sólo que ambas han dibujado sus propios perfiles, poniendo el acento en aspectos diferentes, según les ha convenido. Bien puede decirse, entonces, que los hombres de la América Sajona se caracterizan por ser "idealistas prácticos", mientras los de América Latina por ser "prácticos idealistas". Unos han adaptado las ideas a su realidad, de donde su seguridad, $y$ otros han tratado de adaptar 
su realidad a las ideas, de donde su accidentalidad. El camino a seguir en las relaciones entre ambas Américas es el camino de la comprensión mutua, para que alguna vez, libres de antagonismos, podamos hablar con justicia de una cultura americana sin más.

¿Cuál es, entonces, la tarea para una posible filosofía americana? Al europeo, como se ha dicho antes, se le han cerrado casi todas las posibilidades; según Sartre, en ciertas situaciones, sólo le cabe una alternativa, que es la muerte. Sin embargo, se trata de que, como en otras ocasiones, puede elegir la vida. América, por su posición particular, puede aportar entonces a la cultura la novedad de sus experiencias. Estas experiencias dilucidadas y clarificadas por nuestra filosofía pueden aportar la verdad de América, una verdad que no podrá ser ni inferior ni superior, sino simplemente su verdad, su auténtica y sincera verdad.

$\mathrm{Y}$ aún hay más; debemos darnos cuenta de que la causa fundamental de la crisis europea es la ruptura de las relaciones'entre la teoría y la práctica. Toda comunidad necesita tener un fundamento moral de sus actos materiales, pues una humanidad sin ideas que justifiquen tales actos poco se diferencia de la animalidad. "La filosofía tiene como misión la de abstraer estas ideas de la propia realidad que la circunda elevándolas a modelos que sirvan de guía y justificación a actos puramente materiales." Por esto las crisis siempre han sido crisis de ideas; la solución de las crisis sólo pueden darla nuevas ideas. El hombre, tanto en su aspecto individual como en su aspecto social, ha recobrado, en diversas ocasiones de su his: toria, el equilibrio necesario gracias a una metafísica que ha desempeñado la tarea señalada.

Asi, una posible filosofía americana debe tratar, independientemente de su circunstancia, "de alcanzar una nueva coordinación de los campos metafísico y real. El mundo necesita de esta coordinación y América debe cooperar en ella". No debe detenerla el temor de un supuesto fracaso, ni tampoco exagerar sus pretensiones partiendo de una supuesta superioridad. "En esta forma no sólo resolverá sus propios problemas, en lo mucho en que tales problemas le tocan por su relación con la cultura occidental en crisis, sino, además, tomará el justo puesto que le puede corresponder en esta cultura y en la que hemos llamado cultura universal, en la que se conjugue la cultura de todos. los pueblos.

Será a partir de este momento cuando el mundo, como dice nuestro Alfonso Reyes, empezará 'a contar con nos: otros'."

Abelardo Villegas 